\title{
Crystal Growth Measurement
}

National Cancer Institute

\section{Source}

National Cancer Institute. Crystal Growth Measurement. NCI Thesaurus. Code C74948.

The determination of the amount of crystals present in a sample. 